\title{
An empirical investigation of stalled residential sites in England
}

Article

Accepted Version

McAllister, P., Street, E. and Wyatt, P. (2016) An empirical investigation of stalled residential sites in England. Planning Practice and Research, 31 (2). pp. 132-153. ISSN 1360-0583 doi: https://doi.org/10.1080/02697459.2015.1115658 Available at https://centaur.reading.ac.uk/67079/

It is advisable to refer to the publisher's version if you intend to cite from the work. See Guidance on citing.

To link to this article DOI: http://dx.doi.org/10.1080/02697459.2015.1115658

Publisher: Taylor and Francis

All outputs in CentAUR are protected by Intellectual Property Rights law, including copyright law. Copyright and IPR is retained by the creators or other copyright holders. Terms and conditions for use of this material are defined in the End User Agreement.

\section{www.reading.ac.uk/centaur}

\section{CentAUR}

Central Archive at the University of Reading

Reading's research outputs online 


\title{
AN EMPIRICAL INVESTIGATION OF STALLED RESIDENTIAL SITES IN ENGLAND
}

\author{
Pat McAllister \\ Professor of Real Estate \\ Bartlett School of Planning \\ University College London \\ p.mcallister@ucl.ac.uk
}

Emma Street

Lecturer

School of Real Estate \& Planning

University of Reading

e.j.street@reading.ac.uk

Pete Wyatt

Professor of Real Estate Appraisal

School of Real Estate \& Planning

University of Reading

p.wyatt@reading.ac.uk 


\begin{abstract}
Drawing upon a national database of unimplemented planning permissions and 18 in-depth case studies, this paper provides both a quantitative and qualitative analysis of the phenomenon of stalled sites in England. The practical and conceptual difficulties of classifying sites as stalled are critically reviewed. From the literature, it is suggested that planning permission may not be implemented due to lack of financial viability, strategic behaviour by landowners and house-builders and other problems associated with the development process. Consistent with poor viability, the analysis of a national database indicates that a substantial proportion of stalled sites are high density apartment developments usually is located in low house value areas. The case studies suggest that a combination of interlinked issues may need to be resolved before a planning permission can be implemented. These include; the sale of the land to house-builders, re-negotiation of the planning permission and, most importantly, improvement in housing market conditions.
\end{abstract}

\title{
Key words
}

Stalled sites, development, viability, planning

\section{Acknowledgements}

This paper is based on research undertaken on behalf of UK Government. The project 'The impact of s106 planning obligations on growth' was commissioned by the Department of Communities and Local Government and undertaken by Three Dragons Ltd, University College London and the University of Reading. 


\section{Introduction}

A major element of property development is a process of transforming vacant sites into new land uses or obsolete properties into new uses. It involves a linked sequence of events, some of which occur sequentially, others simultaneously and sometimes overlapping. Many actors and institutions are involved in the early stages of the development process including landowners, investors, occupiers, developers, lenders, architects, engineers, surveyors, planners and real estate agents. The process does not take place in a vacuum; it is affected by and contributes to changes in social trends, economic conditions and the regulatory environment. The initial, pre-construction phase might include tests of financial viability, arrangement of development finance, site assembly and land acquisition, design and costing, and securing of the necessary permissions and consents. The interplay between these processes, actors and the macroeconomic context can create complexity, uncertainty and delay, and it is the latter that forms the focus of this paper. Specifically, the research identifies the causes of delay in developing residential sites in England that already have planning consent.

Controversy regarding the interaction of housing supply, economic growth and 'banked', vacant, stalled, dormant or derelict sites has been a recurring feature of British urban policy. Since the global financial crisis, the failure by developers to implement projects that have planning permission has been a source of frustration for central and local government. At a national level, central government has viewed increased housing market and development activity as a key mechanism to stimulate the macroeconomy. In September 2012, the Mayor of London stated that there were 170,000 dwellings in stalled developments in London ${ }^{1}$. He suggested that that these developments were stalled for a number of reasons including an inability to access development and mortgage finance, overpayments for sites and unviable planning obligations.

Drawing upon the research results of a government-sponsored research project, this paper provides an analysis of the nature and causes of stalled development projects. It analyses a national database of stalled projects to identify broad patterns and, in addition, investigates a sample of case studies to identify the detailed factors that may result in lack of progress for schemes with planning permission. The paper therefore begins with a discussion of the, perhaps nebulous, concept of a 'stalled' site and discusses the range of factors that can result in the non-implementation of a planning permission. Drawing upon a national database and case studies, the third section sets out the method and data sources used to investigate the scope, types and causes of stalled sites in England. This is followed by a discussion of the findings from the data analysis. Finally, conclusions are drawn.

\footnotetext{
${ }^{1}$ http://www.guardian.co.uk/media/davehillblog/2012/sep/20/boris-johnson-london-housing-crisis-andrew-boff
} 


\section{Defining and explaining stalled sites}

\section{Defining stalled sites}

In 2011 the UK Government ${ }^{2}$ launched the Get Britain Building programme as part of its Housing Strategy. The programme aims to unlock development sites with planning permission that have become 'stalled' in order to deliver up to 16,000 new homes. Stalled sites are defined, albeit quasi-statutorily, as follows:

"Stalled sites (which could be a standalone phase within a wider scheme) will be defined as those where there has been no construction activity on the relevant phase since 1 September 2011 (excluding site clearance / remediation, affordable housing delivery construction where it has been possible to progress this in advance of other elements of the site and / or limited activity to implement or maintain a planning permission)"

The 1 September 2011 specified here is for policy operation reasons; the key point is that a stalled site is judged to be 'shovel ready' (i.e. ready for construction to commence) with a planning permission already in place. In essence, a stalled site is defined as a scheme with planning permission that is not being implemented. However, if we view stalled sites through the framework of an event-event production system model, this definition seems restrictive. In the standard event sequence models of the development process, there are many events that typically precede the award of full planning permission (see Ball, 2010 for a description). Typically the process begins with the identification of a development opportunity, followed by land assembly and acquisition, feasibility analysis, regulatory approval, etc. A definition that defines a site as stalled after planning permission has been obtained means that, what is often perceived to be one of the most time-consuming and difficult elements of the development process, can be omitted from an analysis of stalled sites (Healey, 1992). The Get Britain Building approach narrowly defines development projects as stalled when the regulatory conditions for physical implementation have been fulfilled. Yet it is clear from Healey's model of the development process that there are many planning-related events that precede physical implementation of a development project at which a development opportunity can become stalled (Healey, 1991). The simplified sequence of events outlined below illustrates the potential stages at which delay can occur. Moreover, we note that stages may not occur sequentially, the process can be iterative and some of the stages may not occur at all. For instance, sites may obtain planning permission without being allocated in an adopted plan.

\footnotetext{
${ }^{2}$ The UK Parliament is the primary legislature although many policy-setting responsibilities, including planning, have been devolved to Northern Ireland, Scotland and Wales. Therefore, in this paper, reference is made to English planning and UK Government.
} 
a) Site attains a latent development value.

b) Site is identified as a potential development opportunity.

c) Landowner/developer initiation of development.

d) Potential schemes are conceived and their feasibility assessed.

e) Pre-application discussions with and lobbying of local regulatory authorities and other stakeholders takes place, representations made to planning policy formation processes.

f) Site is allocated for development in a Local Plan or via a Local Development Order.

g) Negotiation of planning obligations occurs.

h) Application for outline planning permission is made.

i) Application for full planning permission is made.

j) Full planning permission is granted.

k) Construction of development commences.

In terms of identifying stalled sites, one key issue is establishing how long these stages normally take. Following the Get Britain Building definition, it might be expected that a site should only be defined as stalled when an abnormal time period has lapsed since the grant of planning consent and the commencement of development activity on-site. A study involving 509 housing schemes (consisting of 10 or more homes) completed in London during 2006 provides a useful indicator of normal delay between planning permission and implementation (Craine, 2012). Bearing in mind the buoyant development market conditions prevalent at this time, the study found that eight months was a typical period between grant of full planning consent and start of construction (DCLG, 2007, 35).

\section{Explaining stalled sites}

One advantage of the Get Britain Building definition is that it is fairly straightforward to classify sites as stalled. However, the narrowness of this definition also needs to be interpreted in the context of its purpose. The definition of a stalled site guides researchers where, in the Popperian sense, to 'shine the torch' in terms of identifying causation. Clearly, when explaining why a development scheme is stalled, certain factors may have different levels of significance at different stages in the site 'production' process.

\section{Planning issues}

Given the objectives of the UK Government to stimulate housing supply in the short-term, the Get Britain Building scheme was essentially targeted at sites where construction could commence rapidly. However, as pointed out above, it is also the case that sites may be 'blocked' much further back in the 'planning pipeline'. For instance, in some situations there can a resolution to grant permission but, for 
whatever reason, an associated legal agreement ${ }^{3}$ that may require landowners provide planning obligations such as social housing as part of the consent has not been agreed between the local planning authority and developer(s). Even further back in the 'pipeline', failure to agree on key issues at preapplication negotiations may mean that sites are stalled because the local planning authority and the applicant cannot reach agreement on key issues. Effectively, the result may be that the site is 'stalled' because of planning obligations at an earlier stage in the planning system. Whilst it seems reasonable to infer that sites stalled at an earlier stage in the planning process are more likely to be stalled for planning reasons, it is also the case that a proportion of such sites are likely to have a long development history in which this may simply be the 'latest instalment'.

\section{Viability issues}

A specific situation seems to be indicated in the Get Building Britain definition of stalled sites; that the developer has obtained planning permission but is currently unable to implement the permission because the development is not (sufficiently) profitable within the terms of its current permission. The implication is that a downturn in market conditions has made a once viable development now financially unviable. Recent UK Government policy has sought to address this 'viability problem' by introducing a series of measures that might render the development viable once again. These include:

- A direct financial subsidy

- A re-negotiation of the legal agreement that often forms part of a planning consent which requires the landowner to contribute towards community and infrastructure services, collectively referred to as 'planning obligations' in England

- A re-negotiation of other terms of the planning consent

In order to kick-start stalled development sites, Government guidance has been issued about how schemes that have stalled for 'financial viability' reasons can be reviewed (HCA, 2012). The guidance suggests that local planning authorities 'review the degree of flexibility' around the delivery of planning components, namely land use, design, master plan, infrastructure and housing provision and carbon reduction. Essentially it encourages local authorities to look again at the planning requirements of these stalled schemes. The Government has also, via the Growth and Infrastructure Act, inserted new sections into the 1990 Town and Country Planning Act which introduce review and appeal procedures in relation to affordable housing requirements that have already been settled in extant planning agreements (DCLG, 2012). These measures, when coupled with a general encouragement to voluntarily re-visit

\footnotetext{
${ }^{3}$ This legal agreement is usually referred to as a 'Section 106' agreement because the legal provision for such agreements was established in s106 of the Town and Country Planning Act 1990 (as amended).
} 
previously agreed planning obligations, introduce the prospect of open-ended renegotiation(s) of not only planning obligations but other previously agreed planning requirements too. Ironically, this renegotiation process can itself (further) stall developments.

\section{Site issues}

There may be other explanations for the non-implementation of permission to develop that are unrelated to the terms of the planning permission, associated planning obligations or, indeed, market conditions. As well as issues related to the physical nature of the site such as drainage, the removal of any contamination, installation of services and infrastructure, Drane (2013) pointed out that sites that appear static to the naked eye might, in in fact, be the locus of substantial development-related activity such as financing and transfers of ownership. 'Strategic' behaviour by developers is also possible. For example, there are anecdotes of landowners agreeing to planning obligations without intending to commence development or to sell land in order to secure the principle of development on the site to avoid higher levels of planning obligations that may be imposed in the future. This is sometimes referred to in the development industry as 'banking a permission': the implication being that the planning permission is 'deposited' until it needs to be 'drawn down' at a later date. Similarly, although there may be further issues to be addressed before construction can commence, a developer or landowner may need to secure planning permission in order to meet the terms of funding or option agreements.

Due to the higher levels of risk they present to developers, sites where it is difficult to develop in phases are more likely to be stalled. In a report for the Office of Fair Trading in 2008, KPMG highlighted such problems with apartment developments with the developer exposed to "capital lock-up linked to inability to phase sales... and greater exposure to uncertainties in demand" (KPMG, 2008, 8). At the nadir of the economic downturn, in a report for the Homes \& Communities Agency, DTZ (2009) concluded that high-density urban development involving development comprising almost entirely of flats was not viable anywhere in the country. In contrast, low density, multi-building schemes are fairly straightforward to phase; the developer retains real options to stop and/or change the development as it is progressing. Such schemes can begin to finance themselves and, therefore, risks from sharp changes in market conditions are much lower. In contrast, for single building, high density schemes, the developer can lose numerous options to re-negotiate the terms of the planning permission and to change the pace of development with the result that the development risks are significantly increased. In a riskaverse market environment, projects with high suspension costs may be more prone to stalling due to market conditions that have produced a substantial increase in the developer's risk premium rather than to prices or planning obligations. 
Whilst there has been little academic literature focussed specifically on stalled sites, there is an established body of work on vacant sites. Motivated by policy concerns about inner city decline, there have been a number of papers by David Adams with collaborators, investigating the effect of ownership constraints on the operation of urban land markets (see Adams, Baum and McGregor, 1988 and Adams, Disberry, Hutchinson and Munjoma, 2001). This work found that urban sites might not be brought forward for development because of a combination of passive ownership (encouraged by low holding costs), fragmented ownership rights and speculative behaviour. Prior to the global financial crisis, in order to promote land supply in what was an increasingly buoyant housing market in the UK, Barker (2004) proposed amendments to the property taxation system to encourage the more rapid re-use of urban sites.

\section{Landowner and developer issues}

Another potential factor is that a proportion of stalled sites have become part of the asset base or 'land bank' of house-building companies. Land banks serve a dual purpose: to provide a resource for the construction of new real estate and to provide a portfolio of assets for land investment. There is a longstanding literature on the issue of land banking by major house building companies (see White, 1986). As early as 1974, it was pointed out in the Investors Chronicle that "[d]espite appearances, house-building is only partially the business of putting up houses. The houses are the socially acceptable side of making profits out of land appreciation". More recently, the Callcutt Review (2007), focussed on house-builders' business models, identified the land inventory needs of the house-builders to ensure a supply of developable land. It noted significant variation in the extent of landholdings. While an average 'holding' consisted of 2.8 years supply of land, one major house-builder held over six years' supply (Callcutt Review, 2007). For some house-building companies there may be a conflict between their different roles as land investment companies and house-building companies. However, it is important not to overplay the relative significance of this factor. Data (provided by Savills) in the Callcutt Review relating to the proportion of land with planning permission owned by house-builders suggested that they owned a relatively small proportion - less than $10 \%$. Clearly, before physical construction can commence, much of the land will still need to be transferred to housing developers.

In addition, following Titman (1985), there is a body of US literature more formally analysing the behaviour of vacant site owners from a real options perspective. Essentially, owners' decisions on whether to sell a site to a developer are analysed in terms of weighing the opportunity costs associated with keeping the site vacant against the expected gain from delaying sale until more favourable market conditions prevail. This body of work suggests that the value of the call option to wait (i.e. hold back land from development) increases in more volatile or uncertain market conditions and so may explain, at least in part, why sites appear increasingly stalled at present. More recent work on the optimal 
phasing and inventory issues in real estate development also suggests that, for owners of large and/or multiple sites, it can be economically rational to phase the release of land incrementally over time (Hughen, Ott and Read, 2012). This type of strategic behaviour by landowners has clear links to the controversy concerning 'land hoarding' by house-building companies discussed above.

Many of the points above were identified in previous research on this area in the 1970s and 1980s. The most similar study to this work was conduct for the DoE in 1978. It drew on a sample of 1,000 sites with a capacity for 623,400 dwellings with an outstanding planning permission for residential development in mid-1975. By 1977, 83\% of sites had been completed, started or were likely to be developed in near future. The two main reasons for non-implementation were planning difficulties and a market downturn. Various aspects of landholding practice (e.g. promoters selling on sites, landbanking) and difficulties involving ownership (e.g. housebuilder bankruptcy) were also significant explanations of non-implementation. The impediments identified then will seem familiar in the contemporary context. In addition to potential unresolved planning issues, other factors identified were that

“...the site may not be adequately serviced, or perhaps some form of shared cost arrangement needs to be negotiated between the relevant public authorities and the developer. The site in question may be particularly difficult to develop physically, possibly involving expensive site preparation work. It may be owned by someone either not capable of building themselves or unwilling to sell to a builder. The site may be in an area where builders feel that the market is not right to produce a viable project." (DoE, 1978, 4)

Acknowledging potential issues of multiple causation, the study found a range of factors related to physical site constraints, planning, market conditions/viability and land ownership problems and strategies as leading to non-implementation of planning permissions. Broadly it was found that the predominant factors related to planning-related issues, ownership problems and strategies as being the predominant factors. In particular, strategies to hold, sell or land bank sites accounted for nearly one third of non-implemented sites with financial issues accounting for approximately $8 \%$. Later, a body of research conducted for the Department of the Environment in the 1980s focussed on the implementation of planning policies. Based on case studies, it highlighted lack of site progression due to the "the occasional reluctant landowner", developer resistance to specific planning policies and infrastructure-related issues (DoE, 1985, 83).

In summary, there are many reasons why sites may not come forward into the construction phase of the development process. However, despite the current political salience of these issues, surprisingly little systematic research has been carried out on the type, location and number of stalled sites. As already discussed, one reason for this is that measuring the duration of development stages is difficult due to a general lack of data, the opaqueness of the market data that are available, and the complexity of the 
processes and actors involved. If the policy objective to increase housing supply is to be achieved, there is a limited evidence base on which to construct related policy. This research paper seeks to determine the number, location and type of stalled sites in England, and to ascertain the reasons why they have become stalled.

\section{Data and Method}

The research utilises two sources of information relating to sites with planning permission that are perceived to be stalled: a national database of construction projects supplied by Glenigan and a case study analysis of specific stalled sites. This mixed methods approach was conceived as a way to build both a broader picture of the prevalence of stalled sites (at the national scale) and to provide an opportunity to 'drill-down' to explore the specific factors stalling schemes at the individual site level. As Fellows and Liu (2008: 28) note, combining qualitative and qualitative approaches in this way can provide a "multi-dimensional view of the subject, gained through synergy".

\section{National database}

Information on schemes that are in the 'development pipeline' is collected and maintained by Glenigan, a private sector provider of construction and property development-related data including planning applications, permissions, construction tenders, contracts and completions. For the purposes of this project, Glenigan supplied a snapshot of data that described the nature, scale and location of 'stalled' development schemes in England as at July 17, 2012. It comprises 1,411 sites totalling 75,534 units and, according to Glenigan, constitutes an estimated $£ 8,959 \mathrm{~m}$ of Gross Development Value as at July 2012. Of the 1,411 sites, the majority $(1,217)$ involve new developments. Of the remainder, 46 are extensions (to existing buildings) and 148 are refurbishments. The dates of the planning applications relevant to the schemes range from August 2000 to March 2012. All are classified as 'large' by Glenigan; meaning that they relate to developments other than 'changes of use' and minor works such as extensions. Permission dates range from 06/07/01 to 29/05/12 (four records did not have permission dates).

\section{$\underline{\text { Case studies }}$}

The purpose of the case studies was to focus on specific stalled projects in order to examine in more depth the rationales and situations of site owners. A total of 18 case studies was deemed adequate in order to ensure projects in different English regions and representing varied types of development were captured.. Although this is a small number relative to the total number of stalled development sites across England, the sample nonetheless represents a broad range of sites in terms of location and size. 
This diversity was also reflected in the composition of the schemes. For example, a number were large, urban extensions incorporating community and commercial facilities as well as large residential elements. At the other end of the scale, there were a number of sites with planning permission for a few dozen dwellings.

Similarly, a diverse range of planning obligations had been agreed across the case study sites. It is important to point out here that the aim of the research was to provide an in-depth evaluation of each site rather than to generate a sample that could be used to make inferences regarding significant differences between different categories of site. Thus, whilst efforts were made to cover a range of value areas and size of schemes, it is not possible to make any inferences about differences in the role of planning obligations between the categories of site. Put simply, the case studies will not provide answers to questions such as "Are planning obligations having different types of impact in large/low value/mixed use sites?" This, in our view, does not devalue the usefulness of the data provided by a selected range of case studies. Indeed individual and unusual or unique cases may reveal much about general processes, whether they are 'scaled-up' or not (see Sayer, 1992, Ettlinger, 2009). However, we do acknowledge that care must be taken not to over-generalise when abstracting results from case studies (Flyvbjerg, 2001, Yin, 2008). The sample of stalled sites was purposively generated from a combination of sites suggested by local planning authorities, developers, a project advisory group and the personal knowledge of the research team. The composition of the sample was therefore not based on random sampling but rather reflected the willingness of individuals to put forward examples to the research team.

We divided the country into three broad value areas:

- 'High' - London and South East

- 'Medium' - South West and East of England

- 'Low' - East and West Midlands, Yorkshire and Humberside and North East and North West

As each case study was submitted, we reviewed whether it was within a local authority that was of a much higher/lower value than the majority of local authorities in the value band. If this was the case, drawing upon DCLG data on local authority house prices, we allocated the case study to a more appropriate value band. Schemes were defined as being either large (100 dwellings or more) or small (less than 100 dwellings). Table 1 summarises the sample of proposed case studies. It shows the total number of dwellings in case study schemes for each house price band, in three types of location - urban, suburban and urban extensions (typically a large scale greenfield development on the edge of an existing 
settlement). For each value band and location type (e.g. urban in the high house price band), the table sets out the total case study schemes in the sample.

Table 1: Potential proposed case studies by location and value area (number of dwellings in italics)

\begin{tabular}{|c|c|c|c|c|c|}
\hline & Urban & Suburban & $\begin{array}{c}\text { Urban } \\
\text { extension }\end{array}$ & $\begin{array}{c}\text { Total } \\
\text { schemes }\end{array}$ & $\begin{array}{c}\text { Total } \\
\text { dwellings }\end{array}$ \\
\hline High house price & 3,600 & 1,600 & 10,500 & 43 & 15,700 \\
\hline Large & 9 & 2 & 4 & 15 & \\
\hline Small & $\begin{array}{l}18 \text { (in } 6 \\
\text { LAs) }\end{array}$ & $\begin{array}{l}10 \text { (in } 3 \\
\text { LAs) }\end{array}$ & & 28 & \\
\hline Medium house price & 3,500 & 2,400 & 15,000 & 36 & 20,900 \\
\hline Large & 7 & 1 & 9 & 17 & \\
\hline Small & 8 & $\begin{array}{l}11 \text { (in } 5 \\
\text { LAs) }\end{array}$ & & 19 & \\
\hline Low house price & 3,900 & 700 & 13,500 & 59 & 18,100 \\
\hline Large & 12 & 2 & 7 & 21 & \\
\hline Small & 26 & 12 & & 38 & \\
\hline Total schemes & 80 & 38 & 20 & 138 & \\
\hline $\begin{array}{l}\text { Total number of } \\
\text { dwellings }\end{array}$ & 11,000 & 4,700 & 39,000 & & 54,700 \\
\hline
\end{tabular}

The initial 'convenient' sample of stalled sites set out in table 1 shows a number of characteristics. $43 \%$ of all stalled sites suggested by local planning authorities etc. are in low house price regions compared with $31 \%$ in high price regions and $26 \%$ in medium price regions. However, the incidence of dwellings in stalled sites is slightly different with fewer dwellings (33\%) in the low price areas and more dwellings (38\%) in the medium price area. Urban extensions account for $15 \%$ of all sites but $71 \%$ of all dwellings and ranged in size from under 1,000 units to more than 4,000 units. $28 \%$ of all dwellings in stalled sites are located in suburban areas with $58 \%$ in urban areas. Very few examples of stalled sites in London were identified. There were 11 non-residential stalled schemes: six of these were in high price areas, four in medium value areas and only one in low value areas.

From this initial sample of 138 suggested case studies, we obtained agreement for a detailed assessment from developers and local authority planners at 18 sites. Having gathered data on the permitted schemes, the assessment also involved semi-structured interviews with representatives from developers/landowners and the local authority planning officer. The sites represent a spread of location types (urban, suburban, greenfield/urban extension) within each of the three value bands (low, medium, high) - broadly representative of their proportions in the sample of 138 schemes.

7 - high value areas

4 - medium value areas

7 - low value areas 
Given commercial and negotiating sensitivities, we reassured the appropriate parties that no individual site or scheme would be identifiable in the research results. The interviews were mainly conducted by telephone during October and November 2012. Since a number of the interviewees expressed a preference for a telephone interviews, the vast majority of interviews were conducted by telephone rather than face-to-face. There did not seem to be any substantive difference in tone and content between the two approaches to the interviews. Two researchers were present at most of the interviews. Both interviewers took notes of the responses. Consistent with the semi-structured approach, the interviews were both informal and exploratory or open-ended in nature.

\section{4. $\quad$ Results}

Number, location and types of stalled sites

In terms of a national picture, Table 2 categorises the stalled developments according to their predominant land use (as assigned by Glenigan). Residential-led schemes account for $94 \%$ of all stalled projects and comprise nearly 72,000 dwellings, representing approximately three quarters of one year's supply the sites. These residential schemes are the focus of subsequent analysis. Table 2 shows that nearly two thirds of stalled residential schemes are apartment-led developments with houses and bungalows accounting for a third and specialist housing (student accommodation and sheltered housing) accounting for around $4 \%$. This can be compared to dwelling completions in 2012/13, which were $24 \%$ flats and $76 \%$ houses $^{4}$.

\footnotetext{
${ }^{4}$ DCLG Live Table 254, https://www.gov.uk/government/uploads/system/uploads/attachment_data/file/199190/LiveTable254.xls
} 
Table 2: Sites in England with planning permission but no construction activity, July 2012

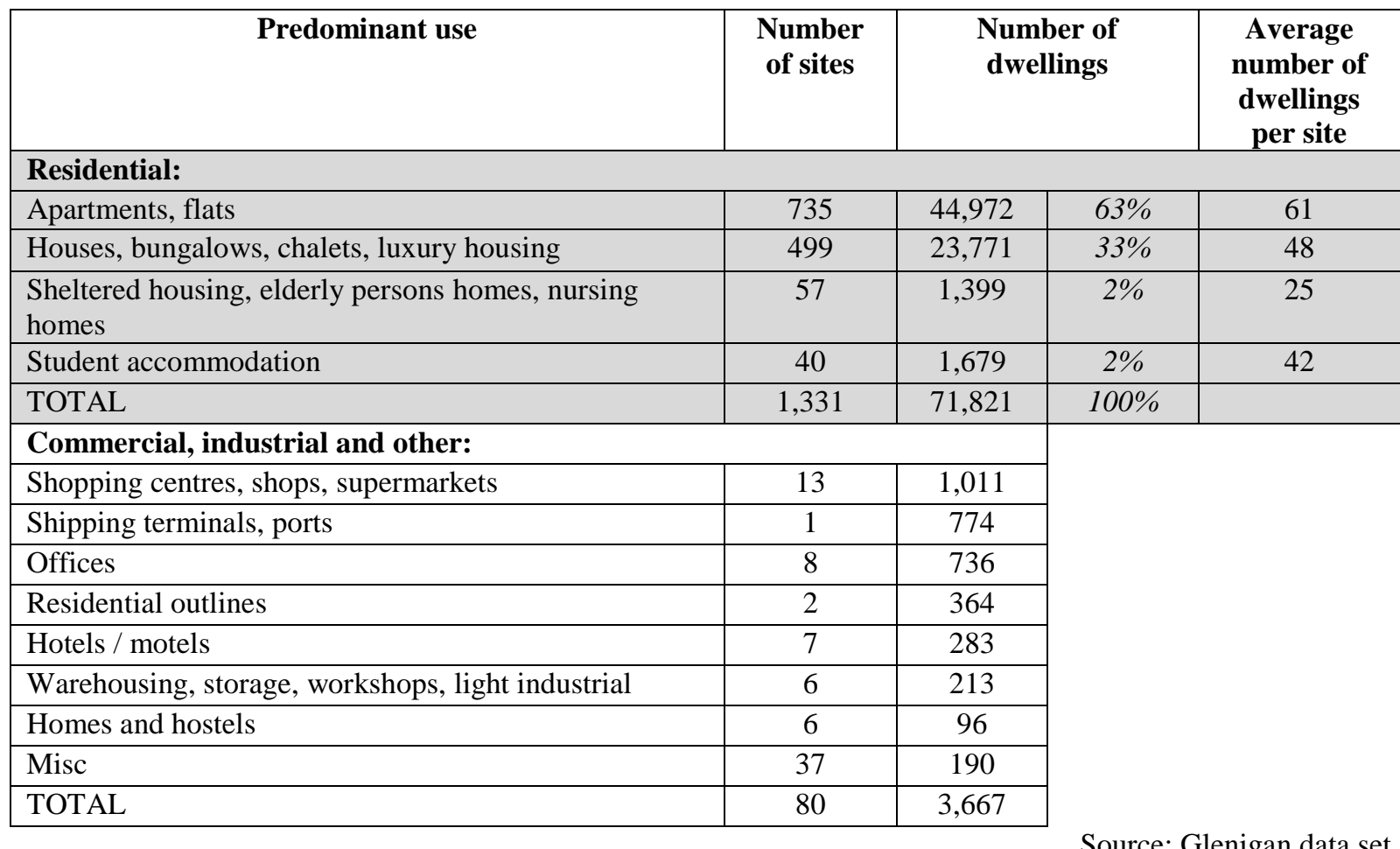

Ignoring the permission granted for one site on 07/12/01, the residential-led stalled developments received planning permissions between 29/02/04 and 29/05/12. Figure 1 shows the numbers of currently stalled schemes categorised by the date of planning permission. Not unexpectedly, a small proportion of stalled sites (in July 2012) were granted planning permission before the global financial crisis. In 2008-9, there was a significant increase in the numbers of sites stalled that were granted permission in these years. This shift has continued for 2010 and 2011. However, given that the planning permissions are relatively recent, a proportion of the non-implemented planning permissions may be due to the 'normal' duration of construction procurement, execution of sales to house-builders etc. rather than any fundamental problems with the schemes. It is also possible that a proportion of planning permissions granted in 2010 and 2011 were renewals or changes to existing schemes. 


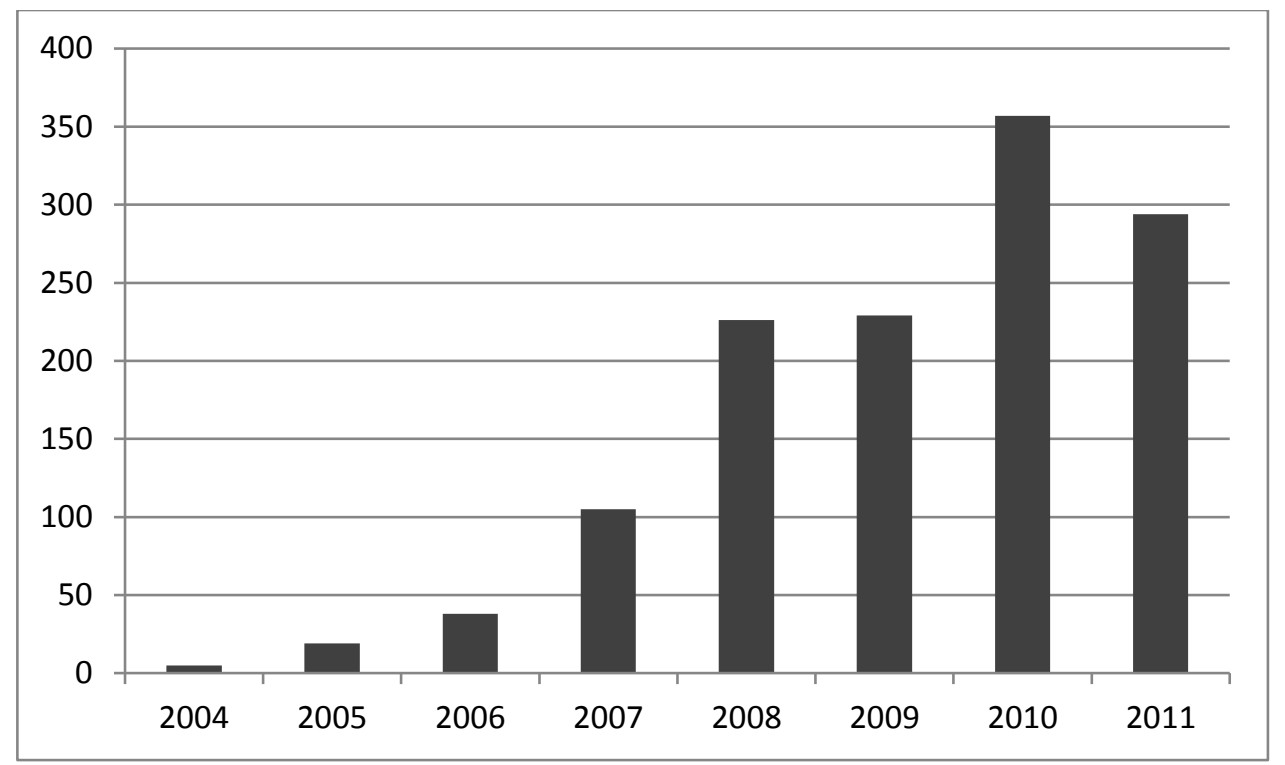

Figure 1: Number of unimplemented planning permissions in England, as of July 2012 (categorised by year planning permission was granted)

Stalled sites that were granted planning permission between October 2010 and September 2011 are classified by region in Table 3 and compared to the number of major permissions granted in the same year. As a proportion of all major decisions, the region with the largest percentage of stalled sites is the North East (17\%), the region with the lowest median house price. It is notable that the proportions for all other regions are fairly consistent, ranging between $5 \%$ and $8 \%$. Broadly, we do not find significant regional differences in the propensity for sites to stall.

Table 3: Stalled sites as a proportion of major residential planning permissions, by region (2010/11)

\begin{tabular}{|l|c|c|c|}
\hline \multicolumn{1}{|c|}{ Region } & $\begin{array}{c}\text { Number of } \\
\text { stalled sites }\end{array}$ & $\begin{array}{c}\text { Major } \\
\text { residential } \\
\text { decisions } \\
\text { (year-end Sept } \\
\text { '11) }\end{array}$ & $\begin{array}{c}\text { Number of } \\
\text { stalled sites as a } \\
\text { percentage of } \\
\text { major } \\
\text { residential } \\
\text { decisions }\end{array}$ \\
\hline Unknown & 5 & - & - \\
\hline East Midlands & 33 & 418 & $8 \%$ \\
\hline East of England & 33 & 482 & $7 \%$ \\
\hline London & 40 & 435 & $8 \%$ \\
\hline North East & 15 & 191 & $17 \%$ \\
\hline North West & 52 & 533 & $6 \%$ \\
\hline South East & 51 & 662 & $5 \%$ \\
\hline South West & 43 & 455 & $7 \%$ \\
\hline West Midlands & 41 & 395 & $8 \%$ \\
\hline Yorkshire and The Humber & 58 & 481 & $7 \%$ \\
\hline Grand Total & 371 & 4,052 & \\
\hline
\end{tabular}

Source: DCLG (Live Table P136) and Glenigan database 
The residential sites were linked to the UK Postcode Directory using the postcode as the common identifier. Not all sites had a valid postcode (there were 128 mismatches). Table 4 shows that most of the stalled sites are located within urban settlements with a population of 10,000 or more and in a less sparsely populated hinterland. This rather vague definition comes from the UK Postcode Directory and is based on an Ordnance Survey classification but it illustrates that the majority are located on brownfield sites. Because brownfield sites typically have a higher existing use value than greenfield sites and are more likely to be apartment schemes, they tend to be more marginal in terms of financial viability. It is therefore not surprising that most of the stalled sites are brownfield.

Table 4: Stalled sites by settlement type

\begin{tabular}{|c|c|c|c|c|}
\hline Geographical location & \multicolumn{2}{|c|}{ Units } & \multicolumn{2}{|c|}{ Sites } \\
\hline $\begin{array}{l}\text { Urban settlements with a population of } 10,000 \text { or more and the wider } \\
\text { surrounding area is sparsely populated }\end{array}$ & 50 & $0 \%$ & 4 & $0 \%$ \\
\hline $\begin{array}{l}\text { Small town and fringe areas category and the wider surrounding area is } \\
\text { sparsely populated }\end{array}$ & 93 & $0 \%$ & 7 & $1 \%$ \\
\hline Village and the wider surrounding area is sparsely populated & 199 & $0 \%$ & 11 & $1 \%$ \\
\hline $\begin{array}{l}\text { Hamlet or isolated dwelling and the wider surrounding area is sparsely } \\
\text { populated }\end{array}$ & 86 & $0 \%$ & 5 & $0 \%$ \\
\hline $\begin{array}{l}\text { Urban settlements with a population of } 10,000 \text { or more and the wider } \\
\text { surrounding area is less sparsely populated }\end{array}$ & 51,519 & $72 \%$ & 969 & $73 \%$ \\
\hline $\begin{array}{l}\text { Small town and fringe areas and the wider surrounding area is less sparsely } \\
\text { populated }\end{array}$ & 2433 & $3 \%$ & 91 & $7 \%$ \\
\hline Village and the wider surrounding area is less sparsely populated & 2,450 & $3 \%$ & 68 & $5 \%$ \\
\hline $\begin{array}{l}\text { Hamlet or isolated dwelling and the wider surrounding area is less sparsely } \\
\text { populated }\end{array}$ & 1,076 & $1 \%$ & 38 & $3 \%$ \\
\hline Scotland/NI/Channel Is/IoM & 919 & $1 \%$ & 10 & $1 \%$ \\
\hline No information available & 13,040 & $18 \%$ & 128 & $10 \%$ \\
\hline Grand Total & 71,865 & & 1,331 & \\
\hline
\end{tabular}

It is expected that the level of house prices will also affect the propensity of development projects to stall. Dividing the 2010 median house price for each of the 326 unitary authorities into quintiles and summing the number of stalled units in each reveals a negative correlation between average house price and number of stalled units.

Table 5: Median house prices and stalled sites in England

\begin{tabular}{|c|c|c|c|c|}
\hline Quintile & $\begin{array}{c}\text { 2010 median } \\
\text { house price ( } \mathfrak{f})\end{array}$ & $\begin{array}{c}\text { Number } \\
\text { of local } \\
\text { authorities }\end{array}$ & $\begin{array}{c}\text { Number of stalled } \\
\text { dwellings, July } \\
\mathbf{2 0 1 2}\end{array}$ & $\begin{array}{c}\text { Percentage } \\
\text { of total }\end{array}$ \\
\hline 1 & $73,000-132,000$ & 65 & 24,536 & 35 \\
\hline 2 & $132,000-160,000$ & 65 & 14,248 & 20 \\
\hline 3 & $160,000-195,000$ & 65 & 11,038 & 16 \\
\hline 4 & $195,000-245,000$ & 65 & 11,544 & 16 \\
\hline 5 & $245,000-750,000$ & 66 & 9,212 & 13 \\
\hline Total & & 326 & 70,578 & $100 \%$ \\
\hline
\end{tabular}

Source: DCLG (Live Table 582) and Glenigan 
Table 6 categorises the local authorities in England by the price per hectare of 'bulk' housing land (land parcels in excess of two hectares) as estimated by the Valuation Office Agency (2010 values). Against this appears the number of stalled dwellings in each category. Although it was not possible to match all stalled site locations to local authorities (the mismatch rate was approximately $9 \%$ ), it is clear that the majority of stalled residential development sites are located in the low land value areas. Figure 2 shows the location of the Glenigan stalled sites. The size of the circles is proportionate to the number of units proposed at each site. Underneath the circles the shaded local authority areas show the price per hectare of 'bulk' housing land (land parcels in excess of two hectares) as estimated by the Valuation Office Agency (2010 values). The map overlay reveals the prevalence of stalled residential development sites in the north of England.

Table 6: Housing land values and stalled sites in England

\begin{tabular}{|c|c|c|c|}
\hline Quintile & $\begin{array}{c}\mathbf{2 0 1 0} \text { 'bulk' housing land } \\
\text { values (£) }\end{array}$ & $\begin{array}{c}\text { Number of stalled } \\
\text { dwellings, July } \\
\mathbf{2 0 1 2}\end{array}$ & $\begin{array}{c}\text { Percentage } \\
\text { of total }\end{array}$ \\
\hline 1 & $550,000-1,550,000$ & 37,628 & $59 \%$ \\
\hline 2 & $1,550,001-2,750,000$ & 11,860 & $18 \%$ \\
\hline 3 & $2,750,001-4,450,000$ & 3,095 & $5 \%$ \\
\hline 4 & $4,450,001-7,560,000$ & 8,125 & $13 \%$ \\
\hline 5 & $7,560,001-15,375,000$ & 3,486 & $5 \%$ \\
\hline Total & & 64,244 & $100 \%$ \\
\hline
\end{tabular}

Source: DCLG (Live Table 582) and Glenigan

Therefore, aside from the North East no major regional variation was found in the propensity of sites to be stalled. However, and perhaps not surprisingly, Tables 5 and 6 suggest that a key issue is local house prices and land values. 
Figure 2: Location of stalled sites in relation to the value of housing land

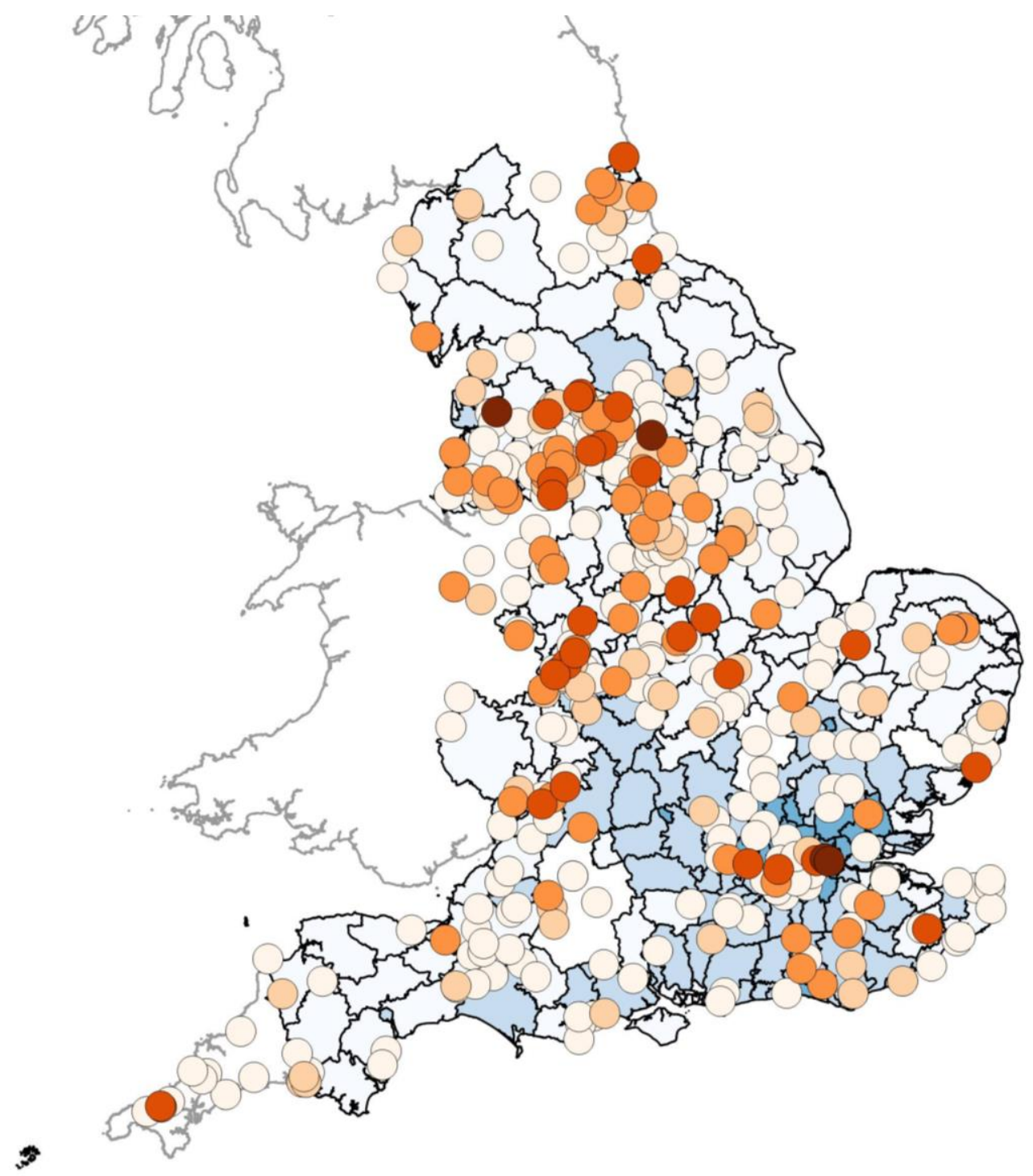

Stalled Sites (No. of dwellings)
1-25
$26-50$
$51-100$
$101-500$
- 501-
2010 Land Values ( $(/ \mathrm{ha})$
$0-1900000$
$11433330-15733330$
1900000 - 3466670
$3466670-6250000$
6250000 - 11433330 
Table 7 shows that, for residential development projects of ten or more dwellings that were approved in the ten-year period from January 2003 to December 2013, approximately two thirds of those which started within six months were housing rather than flats. This proportion drops as the period between approval and start of construction lengthens to the point where $44 \%$ of schemes started after a two-year delay are flats.

Table 7: Starts by Dwelling Types 2003-2013

\begin{tabular}{|l|l|r|r|}
\hline $\begin{array}{c}\text { Period between } \\
\text { approval and start }\end{array}$ & $\begin{array}{l}\text { Scheme } \\
\text { type }\end{array}$ & $\begin{array}{c}\text { Number } \\
\text { of units }\end{array}$ & \multicolumn{1}{|c|}{$\begin{array}{c}\text { Number } \\
\text { of } \\
\text { schemes }\end{array}$} \\
\hline \multirow{2}{*}{ Less than 6 months } & Flats & 238,584 & 4,127 \\
\cline { 2 - 4 } & Houses & 453,221 & 7,265 \\
\hline \multirow{2}{*}{ - 12 months } & Flats & 67,610 & 1,149 \\
\cline { 2 - 4 } & Houses & 98,482 & 1,597 \\
\hline \multirow{2}{*}{ 2 - 24 months } & Flats & 50,718 & 715 \\
\cline { 2 - 4 } & Houses & 53,897 & 837 \\
\hline More than 24 months & Flats & 30,374 & 403 \\
\cline { 2 - 4 } & Houses & 40,062 & 519 \\
\hline
\end{tabular}

(Source: Glenigan)

Construction began on schemes totalling 100,000 units per annum on average over the ten-year period (note that this figure excludes schemes of less than ten units). Concentrating on schemes that have stalled, Figure 3 illustrates, in the first two sets of columns, the number of flat and housing schemes that were put on hold at some point during the ten-year time period. The second two columns show the number of schemes on hold at the end of the period and the last two columns show the number of schemes that were either cancelled before construction started or abandoned at some point after construction had begun. The prevalence of flat schemes is clear to see, as is the small to medium sized schemes of 11 to 50 units. It should be noted, however, that large residential schemes such as urban extensions may involve several planning applications and construction tendering processes. Consequently, the gradual 'building out' of these large developments may appear as a series of smaller schemes in the Glenigan database. 
Figure 3: Stalled, abandoned and cancelled residential development, 2003-2012 (Source: Glenigan)

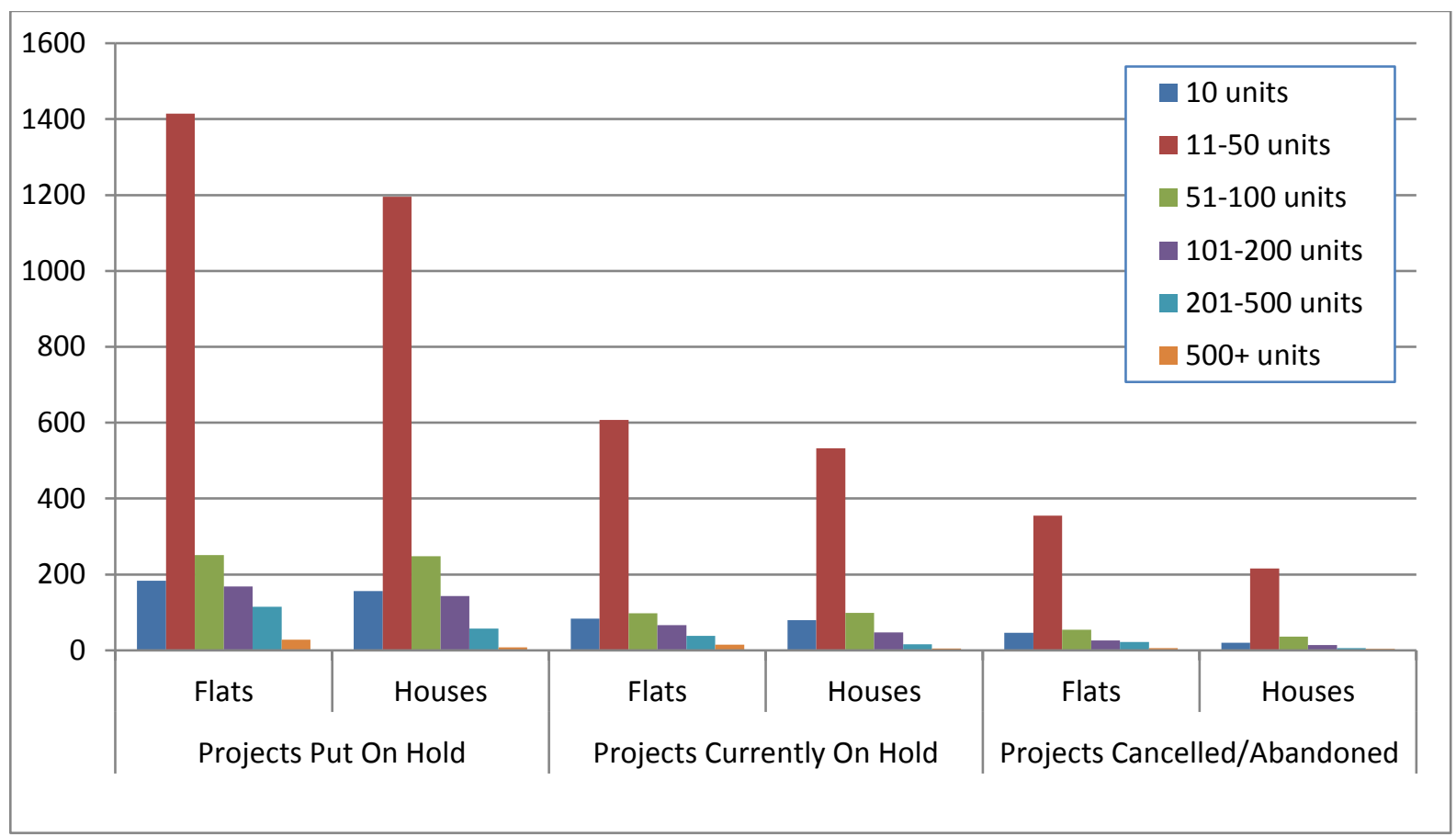

Case study results

Turning to look at the more site-specific scale, the 18 case studies can be broadly categorised as follows (the definitions have been devised for this study):

- $\quad$ Large-scale strategic greenfield development (1,000 or more dwellings) 4

- $\quad$ Significant greenfield scheme with 100 or more dwellings 4

- $\quad$ Small greenfield scheme (99 or fewer dwellings) 2

- $\quad$ Large urban redevelopment/regeneration site (100+ dwellings) 3

- $\quad$ Small urban redevelopment/ regeneration site (99 or fewer dwellings) 4

- $\quad$ Urban infill - 'clean site' 1

The greenfield schemes are similar in character, typically taking the form of urban extensions - housing developments adjoining existing settlements. Depending on their scale, they include different types and levels of transport provision, community and other facilities as well as dedicated open space. The previously developed sites, on the other hand, are more diverse. They include heavily contaminated and difficult-to-develop former factory sites in dense urban (city centre) locations. There are also examples of small (e.g. for 50 dwellings) redevelopment schemes where demolition of an existing building (e.g. a former pub or hotel) is part of the planning permission and urban infill schemes where little is required to bring the site forward for development and development conditions are benign. 
Across the case studies, a diverse range of planning obligations ${ }^{5}$ had been agreed. Housing developments above a certain size must include a proportion of affordable dwellings (social, shared equity or affordable rented housing). Only one scheme above the local site size threshold had agreed no provision for affordable housing, and this was on viability grounds. Where affordable housing was sought, the amount varied, although not as much as expected given the range of market values and development conditions found in the case studies.

While sample sizes were too small to draw any statistical inferences, the expected pattern of higher levels of affordable housing in higher value areas was found. In the high and medium value areas, seven out of ten s106 agreements required between $20 \%$ to $30 \%$ of the total number of units to be affordable with three over 30\%, and the highest being $40 \%$. In the low value area, $20 \%$ to $25 \%$ was the most common proportion although there was one scheme at $0 \%$ and one with a requirement for more than $30 \%$. Planning obligations other than affordable housing were scheme-specific, depending on measures required to mitigate the impact of the development; the larger the scheme, the more diverse the requirements. These included the expected types of planning obligations; highways works, public transport and education contributions, community facilities, public art, play areas and recreation facilities, etc.

As well as variety in the make-up of the contributions required, the case studies varied in the amount of contribution per dwelling, as the following analysis illustrates:

- Small scheme/high value area - $£ 3,700$ per dwelling (no affordable housing - below threshold)

- Large scheme/medium value area $-£ 13,000$ per dwelling $+30 \%$ affordable housing

- Large scheme/high value area - $£ 2,800$ per dwelling $+35 \%$ affordable housing

- Small scheme/low value area - $£ 3,000$ dwelling $+25 \%$ affordable housing

- Large scheme/low value area - $£ 1,800$ per dwelling $+0 \%$ affordable housing

\section{Scheme histories}

Although each site had its own particular 'journey' through the development and planning processes, there are some similarities in the time and effort required to achieve a planning permission. There were several examples of schemes that had taken over ten years from an initial allocation in a development

\footnotetext{
${ }^{5}$ These are agreed under section 106 of the Town and Country Planning Act and are therefore usually referred to as s106 agreements.
} 
plan to planning permission and at least one example of a scheme that has taken more than 20 years. It is perhaps worth briefly expanding on the latter as an illustration (perhaps extreme) of the ways in which planned development can be delayed. The site - an urban extension in a high value area - is under single ownership used as farmland. It was allocated for housing in a local plan in the mid 1980s as part of a major development area. Legal and site issues relating to utilities and road infrastructure development meant that the first planning application was not submitted until the late 1990s. Further disputes regarding emerging environmental regulation meant that this application lapsed and a second was submitted some eight years later. Then, in 2011, a new Local Plan was published which required a 25 per cent affordable housing allocation which was subsequently raised to 40 per cent. S106 heads of terms were agreed and a resolution to grant was made subject to detailed discussions regarding the S106 agreement, but then a legal issue arose regarding adjacent land. Following the market downturn, the local authority and landowner are currently renegotiating aspects of the s106 agreement. Construction has not yet started.

It is not possible to provide a simple analysis of the dates when the case studies were first 'promoted' for development since some schemes were allocated in a development plan and others were 'windfall sites'; the first time the latter are identified to the planning authority is as a planning application. There can also be complications where the extant planning permission is not the first permission granted on the site. Nevertheless, Table 8 groups the case studies according to the length of time between first securing planning permission and the case study interviews (2012).

Table 8: Length of time since (outline) planning permission was granted ${ }^{6}$

\begin{tabular}{|l|c|}
\hline Number of years & Number of case studies \\
\hline Less than 2 & 3 \\
\hline 3 to 5 & 8 \\
\hline 6 or more & 3 \\
\hline Not yet permitted $^{7}$ & 3 \\
\hline
\end{tabular}

The majority of the case studies had been granted planning permission within the last five years but three had older planning permissions. It is important to bear in mind that some planning permissions that were granted relatively recently may in fact relate to an application first submitted several years earlier.

\section{Reasons for stalled schemes}

\footnotetext{
${ }^{6}$ One case study was composed of a series of small schemes, each with variable planning histories.

${ }^{7}$ In all these cases, there was a resolution to grant permission but the s106 agreement was still being negotiated.
} 
One of the objectives of this research was to investigate the reasons why development sites defined as 'shovel ready' have become stalled. Identifying causation in this type of exercise can be difficult and overall the interviews revealed a complex picture. It was notable that for the 18 case studies, 41 reasons for non-implementation of the planning permission were recorded. This indicates that multiple factors were affecting individual sites. Even isolating as opposed to measuring the contribution of a factor to an observed outcome can be problematic. The results of the interview survey reveal the types of complications that can emerge. In order for a site to be 'shovel-ready', a number of changes may need to occur. In terms of project implementation, the market may need to improve through increases in prices and turnover. Project implementation may require a re-negotiation of the planning permission in order to change the scale and mix of the development and also, in some cases, to reduce the level of planning obligations. In addition, there may be issues relating to the site or with landowners that need to be resolved before a planning permission can be implemented. The interviews reveal examples of all these types of issues and their consequent impact on the negotiation of planning obligations.

An analysis of the case studies shows that changed market conditions are the key reason for sites becoming stalled. However, it is not the only reason and there is usually a combination of factors determining whether a site is stalled or progressing. Table 9 sets out the main reasons put forward for delays in bringing schemes forward (note that there could be more than one reason for each case study). 
Table 9: Reasons for Case Study Schemes Becoming Stalled

\begin{tabular}{|l|c|}
\hline Reason & No. \\
\hline Market conditions & 10 \\
Market values have fallen/sales rates generally down & 1 \\
Development finance difficult to secure & \\
Low sales rates/ market change means that need a different mix of dwellings (e.g. replace & \\
apartments with houses) & 3 \\
\hline $\begin{array}{l}\text { General viability issues } \\
\text { Generally a difficult scheme to make work (e.g. high abnormal costs/low values) }\end{array}$ & 4 \\
'Overpaid' for the site & 2 \\
\hline Ownership issues & 2 \\
$\quad$ Change of owners (and could lead to a completely new scheme) & \\
Third parties with control over part of site/ consortium of developers and/or landowners \\
failing to agree/ change in personal circumstances of landowner & 3 \\
\hline Developer not actively pursuing development & 6 \\
$\quad \begin{array}{l}\text { Waiting for upturn in market, have a better scheme nearby } \\
\text { Sought policy compliant permission but anticipated would not be viable }\end{array}$ & 2 \\
\hline Other issues & 1 \\
\hline Third party actions e.g. unforeseen intervention by a utility & 4 \\
\hline Complex scheme with long lead in times (usually, but not exclusively, large scale schemes) & \\
\hline
\end{tabular}

The analysis confirms that changing market conditions is the primary reason for schemes becoming stalled in the period since 2008/09. Market values have fallen ('house prices have dropped through the floor' was a typical comment from interviewees) and, in line with price drops in some areas, developers quoted price reductions of circa $15 \%$. But rates of sales have also fallen; for example, one interviewee indicated that current sale rates were about $50 \%$ of predicted rates pre-downturn. This may turn a previously implementable s106 agreement into something that cannot be delivered, as the following quote from a developer of a larger greenfield site illustrates, 'the agreement was fair and policy compliant but it was assessed in a rising housing market... '. Some developer/landowners described a situation whereby they were faced with the changed market circumstances and had to decide whether to proceed or not. As one interviewee put it, he was 'waiting for the market to improve'. This can be equally true for the developer (unwilling to risk the expenditure on getting a scheme started) and the landowner (not willing to reduce the price they expect to receive for their land).

However, it was also acknowledged that it was not possible to separate the causal factors neatly and that, in a falling market with reduced sales volumes, a reduced level of planning obligations (especially affordable housing) could improve viability sufficiently to get a scheme underway. Putting aside the problem of high levels upfront infrastructure costs often required to progress large-scale developments, another factor leading to some sites stalling relates to land ownership. This can involve a third party with control over a vital piece of land and/or issues to be resolved within a developer and/or landowner consortium. For instance, in two of the case studies, although planning permission had been granted, the sites were occupied and trading as businesses (one was a hotel and the other a car showroom) so they could not realistically be construed as 'shovel ready'. On one of the larger sites, the developer decided that it would be preferable to agree planning obligations and outline consent as soon as possible 
due to imminent changes in the policy regarding planning obligations. Without any intention to implement the agreed planning consent, the developer did not want to delay obtaining the principle of consent on the site and risk potentially more onerous obligations being imposed by planning officers at a later date. In addition, there were four landowners involved in the scheme and it was difficult to get them all to agree to market the site when land prices were falling. On another large scheme, land ownership issues were still being resolved and the developer did not control all land. Compulsory purchase procedures and negotiations with other landowners were underway. It was also clear in some of the case studies that the existing consent would not be implemented and would have to be renegotiated.

Overall, it was clear that the shift in market conditions had created a range of reactions amongst landowners (usually not house-builders) with the result that consents were unlikely to result in construction activity in the short-term. In April 2015, we conducted a follow up activity to investigate whether the 18 case studies remained 'stalled'. We were unable to access updated information for three of the 18 sites. Whilst re-iterating that it would be inappropriate to generalise from a relatively small number of case studies, the update provides some interesting insights into how schemes with unimplemented planning permissions have fared over a longer time period. Broadly, we find that some schemes have been fully implemented. Such schemes are more likely to be small-scale and in high house/land value areas. Other schemes have been partially implemented. Not expectedly, these tend to be large multi-phase projects. A number of schemes are active in that, whilst construction has not commenced, development-related activity is still taking place. New planning permissions are being sought for expanded projects, planning obligations are being re-negotiated, etc. Finally, some schemes remain essentially mothballed. These tend to be in areas of low land/house values.

In the high land value areas, one of the small suburban schemes was implemented during 2014, while construction has now started on site for a second. A third is due to begin on site imminently, subject to the resolution of a protected species issue. The small 'urban' site was developed as sheltered housing, with $75 \%$ of units now reserved or sold. The remaining three urban small sites are still stalled; one unimplemented permission has expired, another is still current while, for the third, pre-application discussions are on-going about developing it into a larger scheme. The picture for the large high-value area sites is also mixed. One large (100+ dwellings) mixed-use urban scheme was purchased by a Housing Association in 2013 after the developer was unable to meet heads of terms. Outline planning permission for the new scheme was granted in 2014. Of the three large greenfield (urban extension) sites located in high-value areas, one remains stalled, while infrastructure provision has begun on the second site, funded by $£ 30$ million in government subsidies. The third site changed hands post-2012; the first phase of 50 units has been built and the whole site due to be completed in 2023-24. 
In the medium land value areas, two of the large sites were partially completed. For one of these sites, progress in building out units in the lower-value areas had been slowed due to the economic downturn. Following representations, a ten-year extension to the 'longstop date' (by which applicants are required to pay all outstanding pro rata s106 contributions) was approved by the planning authority. A development viability report was submitted for a third scheme under the Growth and Infrastructure Act 2013 to establish whether the affordable housing contributions secured for housing on parts of the site can be removed. In the low-value areas, only one of the case study schemes, a small (76 unit) residential development in an urban area, had been completed. All four of the large (100+ dwellings) sites located in urban areas remain stalled. Viability issues were cited as the reason for lack of progress in one of these cases; another of the large sites is actively being marketed for re-sale. The large site located in a 'suburban' low-value area also remains stalled.

\section{Conclusions}

Albeit at a different scale, the problem of stalled sites is akin to urban regeneration interventions that aim to overcome risk aversion and economic viability problems associated with (re)development in weak economic conditions. With a national rather than a local focus, addressing the housing supply crisis is viewed by the government as part of a wider strategy aimed at 'regenerating' the macroeconomy. A range of stimulus measures has been used, and continues to be introduced, to encourage and enable the house-building sector to increase output. Implicit in the attempts to subsidise stalled projects is the presumption that projects are stalled because they are not financially viable. Hence, through programmes such as Get Britain Building, the Growing Places Fund and the Local Infrastructure Fund among others, public funds are offered to developers to pay for infrastructure costs in order to improve viability. In addition, local planning authorities are pressed to re-negotiate and reduce levels of planning obligations.

While there is a growing raft of policy interventions, policy formation seems to be taking place in an evidential vacuum; essentially the type, nature and causes of stalled projects seem to be poorly understood. At the macro-level, the empirical evidence on the location and type of stalled projects suggests that financial viability is likely to be the primary driver. Stalled projects are more likely to be found in low house value areas and/or higher risk projects and/or projects in sectors that have experienced the largest house price falls. The high proportion of stalled projects in apartment developments is a clear finding in this context. Indeed, claims that use broad-brush figures about the number of units with planning permission do not take into account the fact that a large proportion of schemes are unlikely to be viable. The overarching shifts are that house values have fallen in many areas, developers' and lenders' risk aversion has increased and, as a result, once viable financially feasible projects are no longer feasible. At current market prices and taking into account development 
costs, housing development is not viable on a substantial proportion of what is often defined as housing land supply.

Furthermore, strongly echoing research on non-implemented planning permissions from the 1970s, the case study research suggests that the reasons for many stalled projects may be more nuanced than simply viability. For operational reasons, house-builders need to maintain an inventory of sites in order to manage their workflow. However, some house-building companies may be operating as land investment vehicles as well as house-building businesses. Nevertheless, problems with stalled projects cannot be wholly attributed to house-builder behaviour. Previous research has suggested that housebuilders own a small proportion of stalled sites with planning permission and a number of our case study sites were not owned by house-building companies. Other landowners seem to be exercising their options to delay the sale of their sites. Although a site may appear inactive, it is clear that the lack of physical development may be due to ownership conflicts, problems of land title, land transfers, etc. In addition, we find evidence of landowners 'banking' permissions in order to protect themselves from changes in policy. For this type of scheme, planning permissions need to be re-negotiated before development can commence.

Whilst obtaining planning permission may be a necessary condition for development to take place, it is often not a sufficient condition and it is unlikely that a significant proportion of stalled sites, even if financially viable, could be considered 'shovel-ready'. A better understanding of the typical events that occur after a site has obtained planning permission is needed before we can understand the key barriers to the implementation of a planning permission. Although policy is concentrating on viability as a root cause of stalled sites, the reality is not so straightforward; a range of factors can cause a site to be stalled and causality must be understood for policy interventions to be effective. Macroeconomic conditions in the capital and labour markets; housing demand and supply at national, regional and local levels; the poorly-understood trade-off between house-building and land speculation; and site-specific factors such as land assembly, sunk costs, infrastructure requirements etc., all require further investigation. 


\section{References}

Adams, D., Baum, A. and MacGregor, B. (1988) The Availability of Land for Inner City Development: A Case Study of Inner Manchester, Urban Studies, 25, 62-76.

Adams, D., Disberry, A., Hutchison, N. and Munjoma, T. (2001) Ownership constraints to brownfield re-development, Environment and Planning A, 33, 453-477.

Ball, M. (2010) The House Building Industry: Promoting Recovery in Housing Supply, A Report for the Department of Communities and Local Government, April, 2010.

Barker, K. (2004) Review of housing supply: securing our future housing needs, Interim ReportAnalysis, HM Treasury, London.

Craine, T. (2012) Barriers to housing delivery: what are the market-perceived barriers to residential development in London? December 2012, Greater London Authority.

DCLG (Department for Communities and Local Government) (2007) The Callcutt review of housebuilding delivery, Communities and Local Government Publications, London.

DCLG (Department for Communities and Local Government) (2012) Section 106 affordable housing requirements: review and appeal, April 2013, Department for Communities and Local Government, London.

Department of the Environment (1978) Land Availability: A Study of Land with Residential Planning Permission, The Economist Intelligence Unit.

Department of the Environment (1985) The Implementation of Planning Policies and the Role of Development Plans: Report to the D.O.E Volume 2, Planning Policy Implementation in Greater Manchester and the West Midlands.

Drane, J. (2013) The State of Contemporary Property Development Theory, Paper presented at the Pacific Rim Real Estate Society (PRRES) Conference, January, 2013.

DTZ (2009) Assessment of Scope for Affordable Housing Delivery from s106 in a Post Credit Crunch Residential Land Market, Final Report to the Homes and Communities Agency, June 2009.

Ettlinger, N. (2009) Problematizing the presentation of poststructural case study research, or working out the crisis of representation in the presentation of empirics, Environment and Planning A, 41,1017-1019.

Fellows, R. F. and Liu, A. M. M. (2008) Research Methods for Construction, Blackwell-Wiley: Oxford. Flyvbjerg, B. (2001) Making Social Science Matter, Cambridge University Press: Cambridge.

HCA (Homes and Communities Agency) (2012) Reviewing the components of stalled schemes, Topic Paper Practice Note T1.2.2, Homes and Communities Agency.

Healey, P. (1991) Models of the Development Process: a Review. Journal of Property Research, 8, 219-238.

Healey, P. (1992). An institutional model of the development process. Journal of Property Research, 9 (1), 33-44. 
Hughen, K., Ott, S., and Read, D. (2012) Optimal Phasing and Inventory Decisions for Large-Scale Residential Developments, Journal of Real Estate Finance and Economics, 45, 888-918.

KPMG (2008) Study Investigating Financing for Homebuilders, Report for Office for Fair Trading. Sayer, A. (1992) Method in Social Science: A Realist Approach Routledge: London and New York.

Titman, S. (1985) Urban land prices under uncertainty, American Economic Review, 75, 505-514.

White, P. (1986). Land availability, land banking and the price of land for housing: a review of recent debates. Land Development Studies, 3, 101-111.

Yin, R. K. (2008) Case Study Research: Design and Methods, $4^{\text {th }}$ Ed. Sage: London, Delhi and New York. 